\title{
Docosahexaenoic acid prevents dendritic cell maturation and in vitro and in vivo expression of the IL-12 cytokine family
}

Weimin Kong ${ }^{1,2}$, Jui-Hung Yen², Evros Vassiliou ${ }^{3}$, Sabina Adhikary ${ }^{1,2}$, Miguel G Toscano ${ }^{2}$, Doina Ganea ${ }^{2 *}$

\begin{abstract}
Background: Acute and chronic inflammation play essential roles in inflammatory/autoimmune conditions. Protective anti-inflammatory effects of the $n-3$ fatty acids docosahexaenoic acid (DHA) and eicosapentaenoic acid (EPA) were reported in animal models of colitis, sepsis, and stroke. Since dendritic cells (DC) represent the essential cellular link between innate and adaptive immunity and have a prominent role in tolerance for self-antigens, we sought to investigate the impact of DHA on DC maturation and proinflammatory cytokine production.

Methods: Murine bone marrow-derived DC were treated with DHA and stimulated with various toll-like receptor (TLR) ligands. Flow cytometry was used to determine the levels of surface maturation markers and endocytic activity. Cytokine expression and secretion were measured by real-time RT-PCR and ELISA assays. PPAR $\gamma$ and NF $\kappa$ B activity in nuclear extracts were determined by binding to specific oligonucleotide sequences using ELISA-based assays. In vivo effects of DHA were assessed in splenic DC from LPS-inoculated mice maintained on a DHAenriched diet.
\end{abstract}

Results: DHA maintained the immature phenotype in bone marrow-derived DC by preventing the upregulation of MHCII and costimulatory molecules (CD40, CD80 and CD86) and maintaining high levels of endocytic activity. DHA inhibited the production of pro-inflammatory cytokines, including the IL-12 cytokine family (IL-12p70, IL-23, and IL27), from DC stimulated with TLR2, 3, 4, and 9 ligands. DHA inhibition of IL-12 expression was mediated through activation of PPAR $\gamma$ and inhibition of NF $\kappa$ Bp 65 nuclear translocation. DHA exerted a similar inhibitory effect on IL12 and IL-23 expression in vivo in LPS-inoculated mice maintained on a DHA-enriched diet.

Conclusions: Exposure of bone marrow-derived DC to DHA resulted in the maintenance of an immature phenotype and drastic reduction in proinflammatory cytokine release. DHA inhibited the expression and secretion of the IL-12 cytokine family members (IL-12p70, IL-23 and IL-27), which play essential roles in the differentiation of the proinflammatory Th1/Th17 effector cells. The effect of DHA on IL-12 expression was mediated through activation of PPARy and inhibition of NF $\kappa$ B. Inhibition of IL-12 and IL-23 expression was also evident in splenic DC from mice fed a DHA-enriched diet, suggesting that dietary DHA acts as an anti-inflammatory agent in vivo.

\section{Background}

In contrast to $\mathrm{n}-6$ polyunsaturated fatty acid (PUFAs) such as arachidonic acid (AA) which mediate predominantly proinflammatory effects, the $n-3$ PUFAs are mostly anti-inflammatory. The anti-inflammatory effects of docosahexaenoic acid (DHA) and eicosapentaenoic acid (EPA) have been attributed initially to the

\footnotetext{
* Correspondence: doina.ganea@temple.edu

${ }^{2}$ Department of Microbiology and Immunology, Temple University School of Medicine, 3500 North Broad Street, Philadelphia, Pennsylvania 19140, USA
}

inhibition of COX mediated metabolism of AA. More recently, DHA and EPA were shown to be the precursors of potent anti-inflammatory derivatives such as resolvins and protectins [reviewed in [1-8]].

DHA and EPA are obtained primarily from diet but are also synthesized endogenously in the liver from $\alpha$ linoleic acid through a series of desaturation and elongation reactions. Circulating free fatty acids enter cells, followed mostly by esterification via acyl-CoA transferase into membrane-residing 2-lysophospholipids $[4,8]$. It has been proposed that following proinflammatory signaling,
C Biomed Central 
DHA is cleaved from membrane phospholipids by a calcium-independent phospholipase and processed by 15 lipoxygenases (15-LOX) into protectins and D-series resolvins [reviewed in [4,9]]. In addition, circulating n-3 fatty acids also represent an important source of antiinflammatory mediators, as reported in a recent study showing rapid accumulation of circulating DHA and EPA in peritoneal inflammatory exudates [10].

Most of the studies related to the anti-inflammatory activities of $\mathrm{n}-3$ fatty acid derivatives, i.e. resolvins and protectins, have been focused on their effect in resolving inflammation mostly through reduction in neutrophil trafficking and upregulation of macrophage-mediated removal of apoptotic cells [reviewed in $[6,9,11,12]]$. Few studies reported effects of $n-3$ fatty acids on dendritic cells (DC) [13-15]. DC represent the essential cellular link between innate and adaptive immunity. Resident DC activated by pathogens exhibit high endocytic capacity. Following TLR signaling, conventional DC upregulate the expression of MHC and costimulatory molecules, produce proinflammatory cytokines and chemokines, and undergo a change in chemokine receptors. As a result, activated DC migrate to lymph nodes where they stimulate naïve cognate $\mathrm{T}$ cells. In addition, DC can also function as inducers and maintainers of tolerance to self antigens following uptake of apoptotic cells and induction of anergic or regulatory $T$ cells [reviewed in [16,17]].

Through direct release of proinflammatory factors and induction of proinflammatory Th1/Th17 effectors, DC play an essential role in inflammatory/autoimmune conditions. Therefore, the identification and characterization of endogenous and/or exogenous anti-inflammatory agents such as the n-3 fatty acids and their derivatives represents an active field of research with significant therapeutic potential. In the present study we determined that exposure of conventional (myeloid) DC to DHA contributes to the maintenance of an immature phenotype and prevents expression of proinflammatory cytokines through PPAR $\gamma$ activation and inhibition of $\mathrm{NF} \kappa \mathrm{B}$ nuclear translocation. We also observed a similar reduction of IL-12 family cytokines in vivo in splenic DC obtained from mice maintained on a DHA-enriched diet.

\section{Materials and methods Mice}

B10.A (6 to 10 weeks old) and C56BL/6 (4 weeks old) mice were purchased from Jackson Laboratory (Bar Harbor, ME). Mice were handled and housed in accordance with the guidelines of the Temple University Animal Care and Use Committee.

\section{Reagents}

Lipopolysaccharide (LPS) (Escherichia coli O26:B6), polyinosinic-polycytidylic acid (PolyI:C), peptidoglycan (PGN), fluorescein isothiocyanate (FITC)-conjugated dextran and streptavidin-peroxidase were purchased from Sigma-Aldrich (St. Louis, MO). CD11c MicroBeads were purchased from Miltenyi Biotec (Bergish-Gladbach, Germany). CpG ODN 1826 was purchased from InvivoGen (San Diego, CA). Recombinant murine GM-CSF, IL-12, TNF $\alpha$, IL- 6 and CCL-4 were purchased from Peprotech Inc (Rocky Hill, NJ). The ELISA kit for murine IL-27p28 was purchased from R\&D Systems (Minneapolis, MN). DHA, GW9662, Rosiglitazone (Rosi) and peroxisome proliferator activated receptor $\gamma$ (PPAR $\gamma$ ) transcription factor assay kit were purchased from Cayman Chemical (Ann Arbor, MI). Capture and biotinylated anti-mouse IL-23 antibody were purchased from eBioscience (San Diego, CA). FITC-conjugated antimouse CD80, CD86, CD40, MHCII; recombinant mouse IL-10; capture and biotinylated anti-mouse IL-12/p70, IL-6, TNF $\alpha$, IL-10 and CCL-4; and TMB Substrate Reagent Set were purchased from BD PharMingen (San Diego, CA). Nuclear extract kit and TransAm NF $\kappa$ B p 65 transcription factor assay kit were purchased from Active Motif North America (Carlsbad, CA). Anti-I $\kappa \mathrm{B} \alpha$ mouse $m A b$ were purchased from Cell Signaling Technology, Inc (Danvers, MA). Anti-GAPDH rabbit mAb were purchased from Fitzgerald Industries International (Concord, MA). Goat anti-rabbit and goat anti-mouse antibodies conjugated to infrared dye were purchased from LI-COR (Lincoln, NE).

\section{Generation and purification of DC from bone marrow}

$\mathrm{DC}$ were generated from bone marrow. Briefly, femur and tibiae were removed from 6- to 8-wk-old male B10.A mice. Both ends of the bones were cut open and bone marrow cells were flushed out and washed with ice-cold RPMI 1640 medium (Invitrogen Life Technologies Research Laboratory). $2 \times 10^{6}$ bone-marrow cells were cultured in $100 \mathrm{~mm}$ petri dishes containing $10 \mathrm{ml}$ RPMI 1640 medium supplemented with $10 \%$ heat-inactivated FBS (Atlanta Biologicals, Norcross, GA), 2 mM L-glutamine, and $20 \mathrm{ng} / \mathrm{ml}$ recombinant GM-CSF. After three days, another $10 \mathrm{ml}$ of complete medium containing GM-CSF was added to each dish. On day 7 the non-adherent cells were harvested and purified by immunomagnetic sorting with anti-CD11ccoated magnetic beads using the autoMACS system according to the manufacturer's instructions (Miltenyi Biotec). The purity of the sorted cells was determined by FACS analysis (>96\% for CD11c+ cells).

FACS Analysis

Cells were subjected to FACS analysis in a 3-color FACSCalibur (BD Biosciences, Mountain View, CA). Data were collected for 10,000 cells and analyzed using Cellquest software from BD Biosciences (San Jose, CA). DC were cultured in 12 -well culture plates $\left(1 \times 10^{6} / \mathrm{ml}\right)$ and pretreated with $50 \mu \mathrm{M}$ of DHA for $24 \mathrm{~h}$, followed by LPS $(0.1 \mu \mathrm{g} / \mathrm{ml})$ for an additional $24 \mathrm{~h}$. DC were collected, washed with PBS and incubated for 30 minutes 
at $4^{\circ} \mathrm{C}$ with anti-CD80 FITC, anti-CD86 FITC, antiCD40 FITC, anti-I-E ${ }^{\mathrm{k}}$ FITC. The specificity of the primary Abs was established with appropriate isotypematched controls.

\section{Endocytosis}

Endocytosis was measured as the cellular uptake of FITC-dextran (Sigma-Aldrich) and was quantified by flow cytometry. Briefly, DC $\left(5 \times 10^{5}\right.$ cells/well $)$ were incubated in medium containing FITC-dextran $(0.5 \mathrm{mg} /$ $\mathrm{ml}$; molecular mass $40 \mathrm{kDa}$ ) for $2 \mathrm{~h}$ at $37^{\circ} \mathrm{C}$. As a negative control, $\mathrm{DC}$ were precooled to $4^{\circ} \mathrm{C}$ prior to incubation with FITC-dextran at $4^{\circ} \mathrm{C}$ for 2 hours. Subsequently, incubated cells were washed 3 times with cold PBS and analyzed by FACS.

\section{Cytokine and chemokine ELISA}

Cytokine production was determined by sandwich ELISA. DC were cultured in 12 -well culture plates $(1 \times$ $10^{6} \mathrm{cells} / \mathrm{ml}$ or $2 \times 10^{6}$ cells $/ \mathrm{ml}$ ) and pretreated with various concentration $(0.1,1,10,25,50 \mu \mathrm{M})$ of DHA for $24 \mathrm{~h}$, followed by LPS $(0.1 \mu \mathrm{g} / \mathrm{ml})$ for 12 or $24 \mathrm{~h}$. Supernatants were harvested and subjected to ELISA. The detection limits were: $15 \mathrm{pg} / \mathrm{ml}$ for IL-6, TNF $\alpha$, and IL$10,30 \mathrm{pg} / \mathrm{ml}$ for IL-23 and IL-12p70, $20 \mathrm{pg} / \mathrm{ml}$ for CCL4 and $4.7 \mathrm{pg} / \mathrm{ml}$ for IL-27.

\section{Real-time RT-PCR}

The expression of p19, p35, p40, IL-27p28, and EBI3 was detected by SYBR Green-based real-time RT-PCR. RNA was prepared from $4 \times 10^{6}$ purified CD11c+ DC using an Ultraspec RNA isolation system according to the manufacturer's instructions (Biotecx Laboratories, Houston, TX). RNA ( $1 \mu \mathrm{g})$ was reversed transcribed to cDNA and subjected to real time PCR. The PCR mixture $(20 \mu \mathrm{l})$, consists of $4 \mu \mathrm{l}$ diluted cDNA, $16 \mu \mathrm{l}$ of SYBR Green containing the PCR master mix and 150 $\mathrm{nM}$ of each primer. Real-time PCR was performed using the Stratagene Mx3005P. The following primers were used: p19 sense, 5'-TGCTGGATTGCAGAGCAGTAA3' and antisense, 5'-ATGCAGAGATTCCGAGAGA-3'; p35 sense, 5'-GAGGACTTGAA GATGTACAG-3' and antisense, 5'-TTCTATCTGTGTGAGGAGGGC-3'; p40 sense, 5'-GACCCTGCCGATTGAACTGGC-3' and antisense, 5'-CAACGTTGCATCCTAGGA TCG-3'; p28 sense, 5'-TCTGGTACAAGCTGGTTCCTGG-3' and antisense, 5'-TAGCCCTGAACCTCAGAGAGCA-3'; EBI3 sense, 5'-GAGGGTCCGGCTTGATGAT T-3' and antisense, 5'-CACGGTGCCCTACATGCTAA-3'; $\beta$-actin sense, 5'-TCCACCACCACAGCTGAGAGG-3' and antisense, 5'-CAGCTTCTC TTTGATGTCACG-3'. The cycling conditions were $95^{\circ} \mathrm{C}$ for $15 \mathrm{~s}, 75^{\circ} \mathrm{C}$ for $1 \mathrm{~min}$, $57^{\circ} \mathrm{C}$ for $30 \mathrm{sec}$, for 40 cycles, followed by a melting point determination or dissociation curves. The expression level of each gene is indicated by the number of cycles needed for the cDNA amplification to reach a threshold. The amount of DNA is calculated from the number of cycles by using standard curves and the results are normalized to $\beta$-actin.

\section{PPAR $\boldsymbol{\gamma}$ binding to PPRE containing oligonucleotides}

Nuclear extracts were prepared as recommended by the manufacturer (Cayman Chemicals) from $5 \times 10^{6} \mathrm{DC}$ treated as described in Results. The amounts of activated PPAR $\gamma$ were determined by using an ELISA based kit with immobilized oligonucleotides containing peroxisome proliferator responsive element (PPRE). $2 \mu \mathrm{g}$ nuclear extract were incubated in each well overnight at $4^{\circ} \mathrm{C}$ without agitation. Treatment with primary Ab specific for PPAR $\gamma$ was followed by a secondary antibody conjugated to HRP and colorimetric readout at $450 \mathrm{~nm}$. Detection antibodies and positive controls were provided with the manufacturer's kit.

\section{$\mathbf{N} \mathbf{F} \kappa \mathbf{B}$ translocation assay}

DC were incubated in $50 \mu \mathrm{M}$ DHA for $24 \mathrm{~h}$ and treated with $0.1 \mu \mathrm{g} / \mathrm{ml}$ LPS for $1 \mathrm{~h}$. Nuclear proteins were prepared using the nuclear extract kit (Active Motif) according to the manufacturer's protocol. The amount of active NF $\kappa$ Bp 65 in the nuclear extract was detected using ELISA based TransAM NF $\kappa$ B kits containing immobilized NF $\kappa$ Bp 65 consensus site oligonucleotides. $5 \mu \mathrm{g}$ nuclear extract was added to each well, followed by primary antibodies that recognize a p65 epitope accessible only in activated p65 bound to target DNA. An HRPconjugated secondary antibody provides a sensitive colorimetric readout quantified at $450 \mathrm{~nm}$. Results are expressed as relative activity, i.e. absorbance values above those observed in samples with no LPS stimulation.

\section{Cell extracts and Western blots}

Whole cell extracts were generated by lysing DC in buffer containing $50 \mathrm{mM}$ Tris- $\mathrm{HCl} \mathrm{pH} 7.4,150 \mathrm{mM} \mathrm{NaCl}$, $1 \mathrm{mM}$ EDTA, 1\% sodium deoxycholate, 0.1\% SDS 1\% Triton X-100, $1 \mathrm{mM}$ PMSF, and protease inhibitor cocktail (Sigma-Aldrich). Samples were run on SDSPAGE gels and transferred onto nitrocellulose membrane. The membrane was probed with primary antibodies against $\mathrm{I} \kappa \mathrm{B} \alpha$ and $\mathrm{GAPDH}$, followed by infrared conjugated secondary antibodies and scanned using the ODYSSEY Infrared Imaging system (LI-COR).

\section{In vivo experiments}

4 wks old C57BL/6 mice (groups of 5) were fed with control diet (no DHA) or DHA-enriched diet $(0.22 \%$ DHA) (Table 1) for 5 wks. $12 \mathrm{~h}$ after inoculation of 50 $\mu g$ LPS i.p., expression of p40, p19, p35, p28 and EBI3 was determined by qRT-PCR in purified splenic CD11c + DC. The DHA supplement, under the trade name DHASCO, was obtained from Martek Biosciences Corporation (Columbia, MD). The diet was produced at Research Diets Incorporated (New Brunswick, NJ).

Purification of splenic CD11c+ DC

Spleens cut into small pieces were incubated in HBSS $\mathrm{w} / \mathrm{Ca}^{+2}, \mathrm{Mg}^{+2}$ containing $0.5 \mathrm{mg} / \mathrm{ml}$ Liberase $\mathrm{TL}$ and 1 
Table 1 Control and DHA diet analysis

\begin{tabular}{lrrrr}
\hline & \multicolumn{2}{c}{ Control Diet } & \multicolumn{2}{c}{ DHA Diet } \\
\hline Protein & gm\% & kcal\% & gm\% & kcal\% \\
\hline Carbohydrate & 20 & 20 & 20 & 20 \\
\hline Fat & 61 & 59 & 61 & 59 \\
\hline Total & 10 & 22 & 10 & 22 \\
\hline kcal/gm & & 100 & & 100 \\
\hline & 4.1 & & 4.1 & \\
\hline Ingredient & & & & \\
\hline Casein, 80 Mesh & gm & kcal & gm & $k c a l$ \\
\hline Casein, Alcohol Extracted & 0 & 0 & 0 & 0 \\
\hline L-Cystine & 200 & 800 & 200 & 800 \\
\hline
\end{tabular}

\begin{tabular}{lllll}
\hline Corn Starch & 150 & 600 & 150 & 600 \\
\hline Maltodextrin 10 & 150 & 600 & 150 & 600 \\
\hline Sucrose & 100 & 400 & 100 & 400 \\
\hline Dextrose & 200 & 800 & 200 & 800 \\
\hline
\end{tabular}

\begin{tabular}{lllll}
\hline Cellulose, BW200 & 50 & 0 & 50 & 0 \\
\hline
\end{tabular}

\begin{tabular}{lrrrr}
\hline Soybean Oil & 0 & 0 & 0 & 0 \\
\hline Safflower Oil, High Oleic & 100 & 900 & 94.5 & 850.5 \\
\hline DHASCO (40\% DHA) & 0 & 0 & 5.5 & 49.5 \\
\hline t-BHQ & 0.014 & 0 & 0.014 & 0 \\
\hline Mineral Mix S10022G & 35 & 0 & 35 & 0 \\
\hline
\end{tabular}

\begin{tabular}{lrrrr}
\hline Vitamin Mix V10037 & 10 & 40 & 10 & 40 \\
\hline Choline Bitartrate & 2.5 & 0 & 2.5 & 0 \\
\hline
\end{tabular}

\begin{tabular}{lllll}
\hline Total & 1000.514 & 4152 & 1000.514 & 4152
\end{tabular}

Total composition of experimental diets per manufacturer's analysis

$\mathrm{mg} / \mathrm{ml} \mathrm{DNase} \mathrm{I} \mathrm{at} 37^{\circ} \mathrm{C}$ for $30 \mathrm{~min}$. Debris was removed by filtering cells through cell strainers $(70 \mu \mathrm{m})$. Spleen CD11c+ DC were purified using the autoMACS system and $\mathrm{CD} 11 \mathrm{c}$ magnetic beads as recommended by the manufacturer (Miltenyi Biotec).

\section{Statistical analysis}

Results are described as mean +/- SD. Comparisons between two groups were done using Student $t$ test, whereas comparisons among multiple groups were done by one way ANOVA. Statistical significance was determined as $p$ values less than 0.05 .

\section{Results}

DHA maintains an immature phenotype in DC

Increased expression of MHCII and costimulatory molecules are hallmarks of DC maturation. To determine whether DHA affects DC maturation, CD11c+ bone marrow-derived DC were pretreated with DHA for $24 \mathrm{~h}$ followed by LPS for an additional $24 \mathrm{~h}$. Immature DC displayed low levels of MHCII, CD40, CD80, and CD86, and expression was dramatically increased following LPS stimulation. DHA prevented the LPS-induced upregulation of MHCII and costimulatory molecules (Fig. 1A).

In contrast to immature $\mathrm{DC}$ which take up antigens efficiently, antigen uptake is significantly reduced in mature DC. We investigated the effects of DHA on the capacity of immature and LPS-matured DC to take up FITC-dextran, and found that DHA prevented the decrease in endocytosis following LPS treatment (Fig. 1B). Taken together, these results suggest that DHA contributes to the maintenance of an immature status in LPS-stimulated DC.

DHA prevents cytokine and chemokine release from LPSstimulated DC

In contrast to immature DC, LPS-treated DC secrete proinflammatory cytokines and chemokines including IL-12p70, IL-23, IL-6, TNF $\alpha$, CCL3 and CCL4, and anti-inflammatory cytokines such as IL-10. To investigate the effect of DHA on cytokine/chemokine production, we pretreated DC with DHA, followed by LPS stimulation. DHA inhibited in a dose-dependent manner the release of the IL-12 cytokine family, i.e. IL-12p70, IL-23 and IL-27 (Fig. 2). We observed a similar DHA inhibition of IL-6, TNF $\alpha$, CCL-4, and IL-10 secretion in LPS-stimulated DC (Fig. 3).

To investigate whether DHA could affect cytokine production in response to signaling through various TLRs, we pretreated DC with DHA, followed by stimulation with LPS (TLR4 ligand), PGN (TLR2 ligand), CpG (TLR9 ligand), poly I:C (TLR3 ligand) and combined $\mathrm{CpG}$ and poly I:C treatment. We observed profound inhibition of both IL-12p70 and IL-23 for LPS, PGN and poly I:C stimulation, and reduction in cytokine production for the combined $\mathrm{CpG}$ and poly I:C treatment (Fig. 4).

\section{DHA prevents IL-12p70 production through effects on}

\section{PPAR $\gamma$ and $\mathrm{NF} \kappa \mathrm{B}$}

In an effort to elucidate the transcriptional mechanisms we focused on the peroxisome proliferator activated receptor $\gamma$ (PPAR $\gamma$ ), which has the capacity to bind unsaturated fatty acids including DHA, and on the $\mathrm{NF} \kappa \mathrm{B}$ signaling pathway.

$\mathrm{DC}$ were pretreated with increasing concentrations of DHA for $24 \mathrm{~h}$, followed by LPS stimulation. Nuclear extracts were tested for PPAR $\gamma$ activation by using a PPAR $\gamma$ regulatory sequence (PPRE)-containing oligonucleotide binding assay. We observed high levels of PPAR $\gamma$ binding in DC treated with DHA concentrations that were inhibitory for cytokine production (Fig. 5A). The specificity of PPAR $\gamma$ binding in DC treated with DHA and LPS was confirmed by use of the specific PPAR $\gamma$ inhibitor GW9662, which reduced binding to 


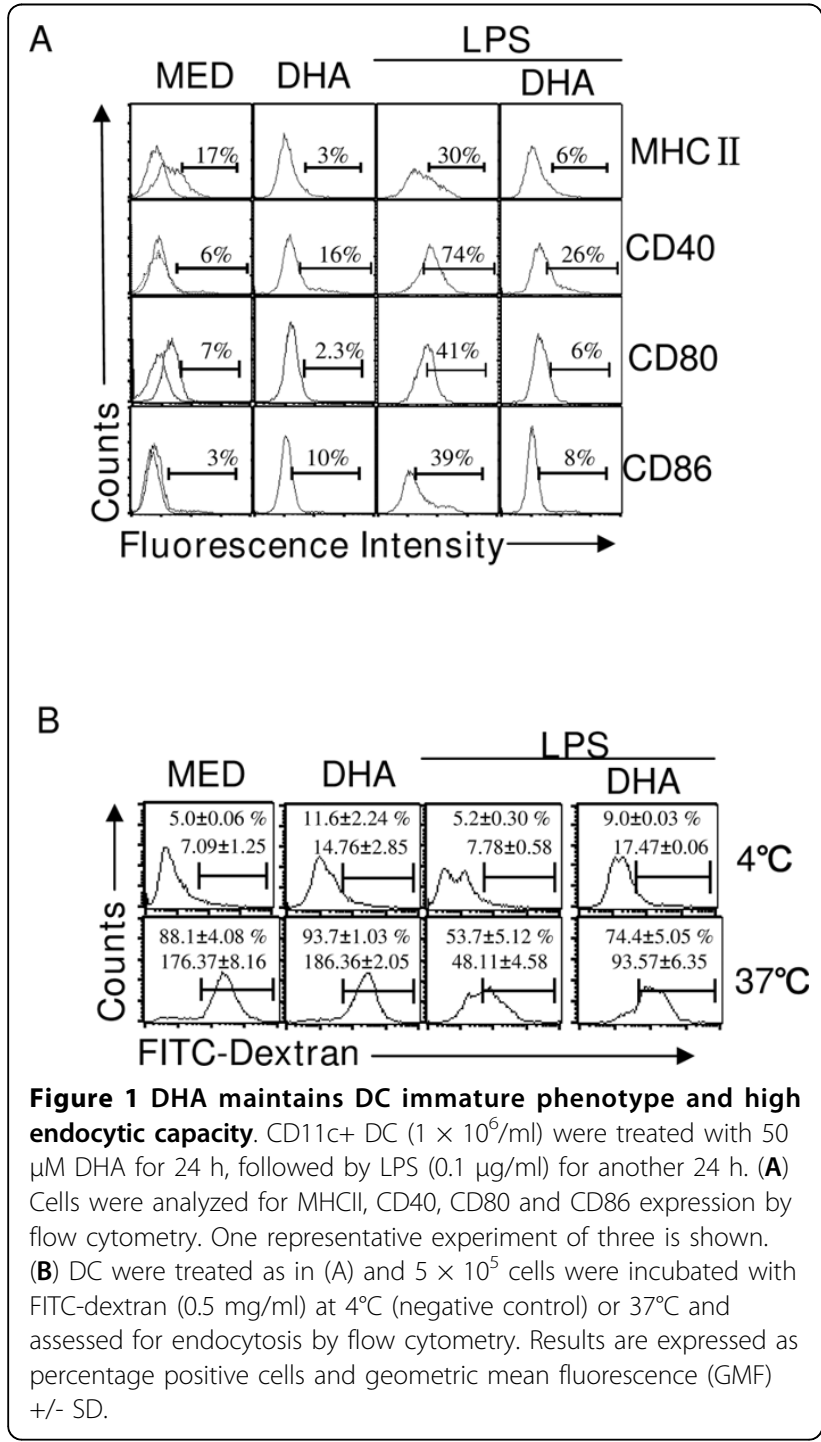

control levels. As a control for PPAR $\gamma$ binding specificity, we used the PPAR $\gamma$ agonist Rosi which induced binding in DC treated with LPS in the absence of DHA (Fig. 5B).

Next, we assessed the involvement of PPAR $\gamma$ in the DHA-mediated inhibition of cytokine production. The PPAR $\gamma$ inhibitor GW9662 did not affect LPS-induced IL-12p70 production (Fig. 5C). PPAR $\gamma$ activation by Rosi prior to LPS treatment resulted in approximately $40 \%$ reduction in IL-12p70 production. As expected, this reduction was abolished by the PPAR $\gamma$ inhibitor GW9662 (Fig. 5C). Similar to Rosi, DHA pretreatment resulted in a reduction in IL-12p70. However, in this case, the reduction was only partially reversed by GW9662 (Fig. 5C), an indication that other factors in addition to PPAR $\gamma$ mediate the inhibitory effect of DHA on IL-12p70 production.
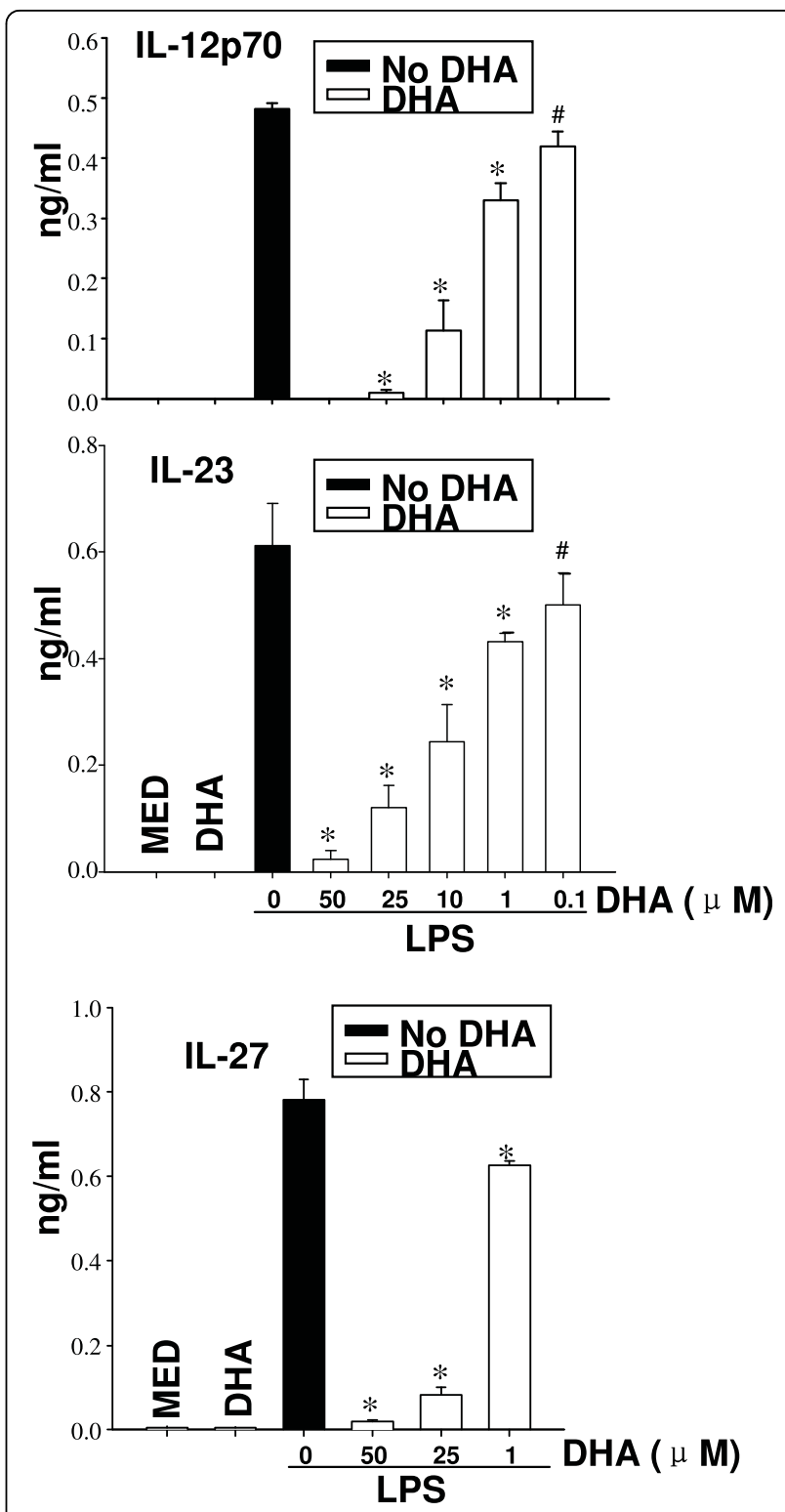

Figure 2 DHA prevents expression of IL-12 family cytokines in LPS-treated DC. DC $\left(1 \times 10^{6} / \mathrm{ml}\right.$ for IL-12p70 and IL-27 and $2 \times$ $10 \% / \mathrm{ml}$ for IL-23) were cultured in the presence of different concentration of DHA for $24 \mathrm{~h}$, followed by LPS for $12 \mathrm{~h}$ (for IL-23) or $24 \mathrm{~h}$ (for $\mathrm{IL}-12 \mathrm{p} 70$ and $\mathrm{IL}-27$ ). Supernatants were subjected to ELISA. Data represent the mean $+/-\mathrm{SD}$. ${ }^{*} p<0.01$, $\# p<0.05$, compared with LPS-treated samples (no DHA).

Since $\mathrm{NF} \kappa \mathrm{B}$ is a major transcription factor for the expression of cytokine/chemokine genes, we evaluated the possible role of DHA on $\mathrm{NF} \kappa \mathrm{B}$ activation in LPStreated DC. Similar to the PPAR $\gamma$ activation assay, we prepared DC nuclear extracts and measured p65 binding to oligonucleotides containing $\kappa \mathrm{B}$ specific sequences. DC treated with LPS exhibited high nuclear $\kappa \mathrm{B}$ binding which was not affected by pretreatment with Rosi (Fig. $6 \mathrm{~A})$, which indicates that p65 nuclear translocation in 

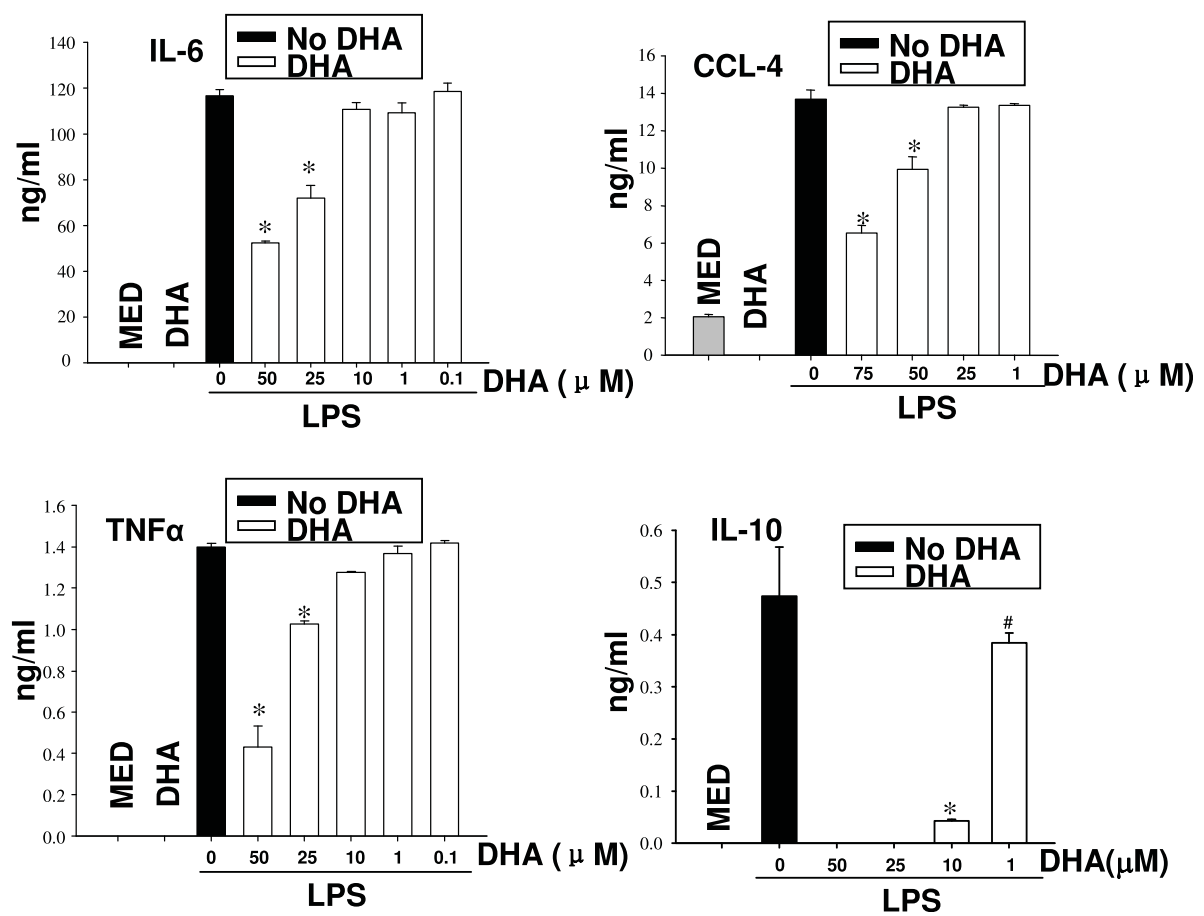

Figure 3 DHA prevents cytokine production in LPS-treated DC. CD11C+ DC $\left(2 \times 10^{6} / \mathrm{ml}\right.$ for IL-10 or $1 \times 10^{6} / \mathrm{ml}$ for TNF $\alpha$, IL- 6 and CCL-4) were treated with various concentrations of DHA for $24 \mathrm{~h}$ followed by LPS $(0.1 \mu \mathrm{g} / \mathrm{ml})$ for an additional $24 \mathrm{~h}$. Supernatants were harvested and assayed for IL-6, CCL-4, IL-10 and TNF $\alpha$ by ELISA. Two independent cultures were tested in triplicate. Results are expressed as mean $+/-$ SD. ${ }^{*} p<$ $0.01, \# p<0.05$, compared to LPS-treated samples (no DHA).

response to LPS is PPAR $\gamma$ independent. In contrast to Rosi, DHA reduced LPS-induced p65 binding by approximately $50 \%$ (Fig. 6A). The inhibitory effect of DHA on $\mathrm{NF} \kappa \mathrm{B}$ translocation may be mediated through the inhibition of $\mathrm{I} \kappa \mathrm{B}$ degradation. Indeed, Western blots confirmed that LPS induced a significant reduction in $\mathrm{I} \kappa \mathrm{B}$, whereas DHA pretreated samples contained higher I $\kappa \mathrm{B}$ levels (Fig. 6B).

In vivo effect of DHA on IL-12 family cytokine expression Mice were maintained on a regular or DHA-enriched diet for 5 weeks, followed by LPS inoculation. Splenic DC were purified and analyzed for expression of IL12p40, IL-12p35, IL-23p19, IL-27p28 and IL-27EBI3. With the exception of EBI3, all other IL-12 family cytokine subunits were significantly reduced in splenic DC from mice on the DHA-enriched diet (Fig. 7). This indicates that, similar to our in vitro results, DHA affects cytokine expression in vivo in splenic DC.

\section{Discussion}

The impact of diets rich in n-3 PUFAs and of DHA and EPA administration has been evaluated in clinical studies and various animal models, with protective effects described in models of colitis, sepsis, and stroke [18-24]. Confirming the protective anti-inflammatory effect of n3 PUFAs, transgenic fat-1 mice expressing a gene encoding an n-3 fatty acid desaturase which enables production of n-3 from n- 6 PUFAs, exhibit low NF $\kappa B$ activity, reduced levels of TNF $\alpha$ and IL-1 $\beta$, and are protected from colitis [25].

The direct effects of DHA or EPA on various immune cell populations are not well studied. Initial reports indicated that DHA favors Th2 differentiation which is in agreement with its inhibitory effect on IL-12 production by $\mathrm{DC}[13-15,26,27]$. In the present study we report on DHA effects on DC phenotype and function. In terms of phenotype, DC treated with DHA and LPS maintain an immature phenotype characterized by low expression of MHCII and costimulatory molecules (CD40, CD80 and CD86). From a functional point of view these phenotypic traits result in poor stimulatory capacity for $\mathrm{T}$ cells.

Exposure to DHA inhibited the production of proinflammatory molecules, i.e. IL-6, TNF $\alpha$, CCL-4, and of the anti-inflammatory cytokine IL-10. This is in agreement with a report on human monocyte-derived DC generated in the presence of DHA [14]. In contrast, Loscher et al [28] reported that conjugated linoleic acid inhibited LPS-induced IL-12 in murine DC through upregulation of IL-10. Therefore, different PUFAs could act through different molecular mechanisms to attenuate the DC proinflammatory response. In agreement 


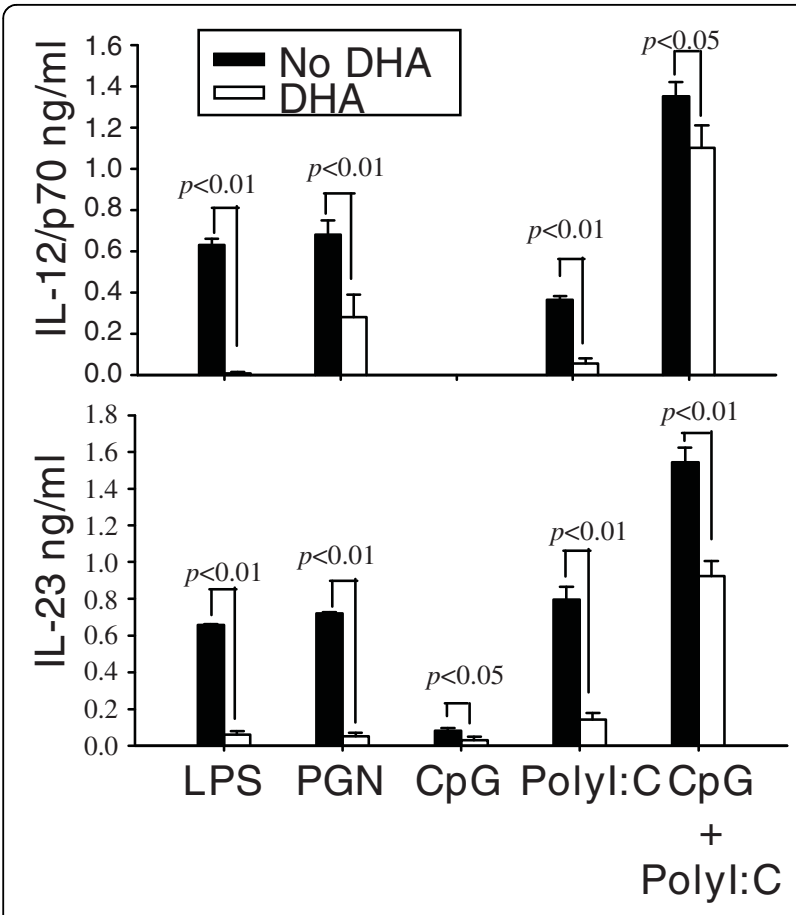

Figure 4 Effects of DHA on IL-12p70 production initiated by signaling through various TLRs. CD11 $\mathrm{c}^{+} \mathrm{DC}\left(1 \times 10^{6} \mathrm{cells} / \mathrm{ml}\right.$ for $\mathrm{IL}-12 \mathrm{p} 70$ and $2 \times 10^{6}$ cells $/ \mathrm{ml}$ for IL-23) were pretreated with $25 \mu \mathrm{M}$ DHA for $24 \mathrm{~h}$ followed by different TLR ligands (LPS $0.1 \mu \mathrm{g} / \mathrm{ml}, \mathrm{PGN}$ $10 \mu \mathrm{g} / \mathrm{ml}$, CpG $1 \mu \mathrm{M}$, poly l:C $50 \mu \mathrm{g} / \mathrm{ml}$, CpG $1 \mu \mathrm{M}+$ poly I:C $50 \mu \mathrm{g} /$ $\mathrm{ml}$ ) for an additional $12 \mathrm{~h}$ (for IL-23) or $24 \mathrm{~h}$ (for IL-12p70). Supernatants were harvested and assayed for IL-12p70 or IL-23 by ELISA.

with several other reports [13-15,27], we found that DHA had a profound inhibitory effect on IL-12p70 production. In addition, we report here for the first time that DHA has a similar inhibitory effect on the other two members of the IL-12 family, i.e. IL-23 and IL-27. IL-23 inhibition could have a significant impact on T cell differentiation in terms of Th17, since IL-23 has been reported to maintain the Th17 functional phenotype [29-32].

The intracellular signaling pathways elicited by DHA and the final transcriptional targets are not known. One possible mediator is PPAR $\gamma$, a nuclear receptor activated by endogenous and exogenous ligands, with multiple physiological functions, including immune regulation [33-35]. Eicosanoids and PUFAs, including DHA, are endogenous PPAR $\gamma$ ligands [36,37]. Highly expressed in DC, macrophages, $\mathrm{T}$ and B cells, PPAR $\gamma$ acts primarily as an anti-inflammatory agent [reviewed in [33-37]]. The model for ligand-dependent PPAR $\gamma$ transrepression of cytokine/chemokine gene expression in macrophages and DC includes ligand-dependent SUMOylation of PPAR $\gamma$ followed by binding and stabilization of corepressor complexes resulting in maintenance of active

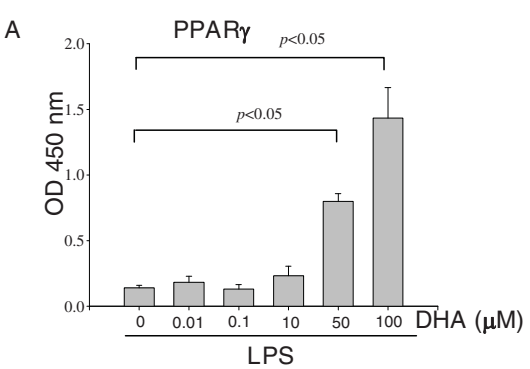

B

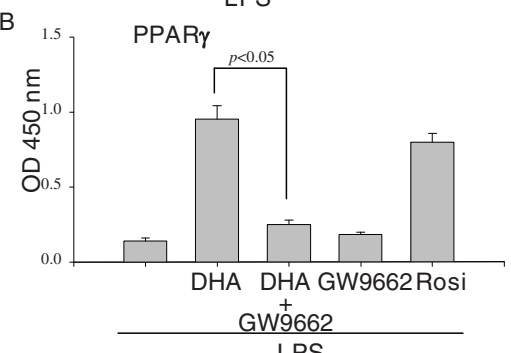

C

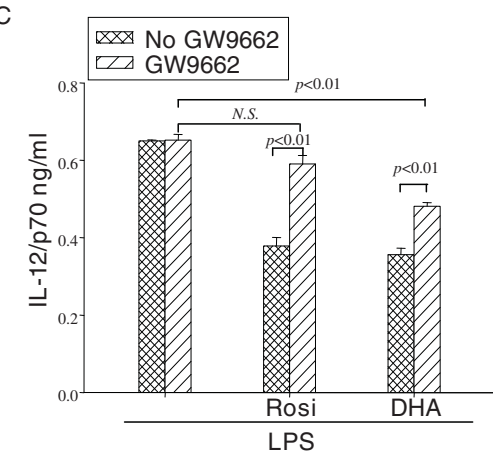

Figure 5 DHA activates PPARy. (A) CD11C+ DC $\left(5 \times 10^{6}\right)$ were pretreated with increasing concentrations of DHA for $24 \mathrm{~h}$, followed by $0.1 \mathrm{\mu g} / \mathrm{ml}$ LPS stimulation for $16 \mathrm{~h}$. Activation of nuclear PPAR was evaluated through binding to oligonucleotides containing PPRE as described in Methods. (B) DC were pretreated with the PPARy inhibitor GW9662 (10 $\mu \mathrm{M})$ for $2 \mathrm{~h}$, followed by $50 \mu \mathrm{M}$ DHA or $1 \mu \mathrm{M}$ of the specific PPARy agonist Rosiglitazone (Rosi) for $24 \mathrm{~h}$, and LPS $(0.1 \mu \mathrm{g} / \mathrm{ml})$ for an additional $16 \mathrm{~h}$. Activation of PPAR $\gamma$ was determined as described in (A). (C) CD11c+ DC $\left(1 \times 10^{6} / \mathrm{ml}\right)$ were pretreated with $4 \mu \mathrm{M}$ GW9662 for $2 \mathrm{~h}$ before the addition of $5 \mu \mathrm{M}$ DHA or $0.4 \mu \mathrm{M}$ Rosi (for $24 \mathrm{~h}$ ) and LPS for an additional $24 \mathrm{~h}$. Supernatants were collected and IL-12p70 production was determined by ELISA.

suppression of inflammatory genes [33]. We observed that DHA concentrations that were effective for IL-12 inhibition also induced PPAR $\gamma$ activation. The inhibitory effect of DHA on IL-12p70 production was partially reversed by the PPAR $\gamma$ inhibitor GW9662. Taken together, these results strongly suggest that the DHA effect on DC expression of IL-12, and presumably other cytokines as well, is mediated, at least partially, through PPAR $\gamma$ activation.

The partial reversal observed with the PPAR $\gamma$ inhibitor led us to consider the involvement of other factors beside PPAR $\gamma$. Since NF $\kappa$ B, readily induced upon TLR 
A

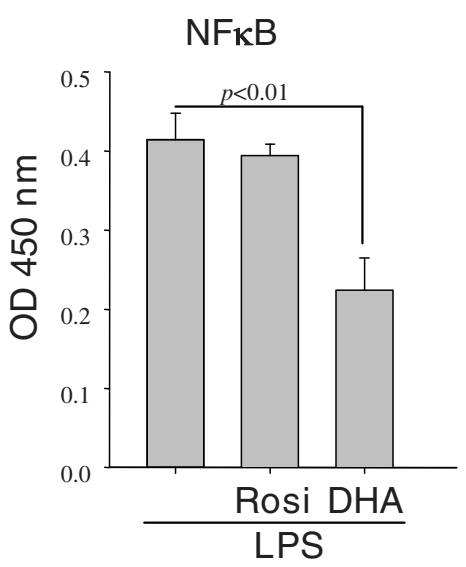

B
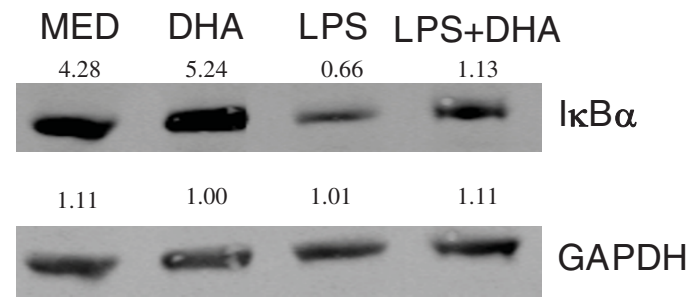

Figure 6 DHA blocks NF $\kappa$ B p65 nuclear translocation. (A) $1 \times$ $10^{7} \mathrm{DC}$ were preincubated with $(50 \mu \mathrm{M}) \mathrm{DHA}$ or $(1 \mu \mathrm{M})$ Rosi for 24 $h$, followed by LPS treatment for $1 \mathrm{~h}$. Presence of NF $\kappa B$ p65 in DC nuclear extracts was determined by binding to $\kappa \mathrm{B}$ containing oligonucleotides. Results are expressed as relative activity, i.e. absorbance values above those observed in the absence of LPS stimulation. (B) DC were pretreated with DHA for $24 \mathrm{~h}$, followed by LPS stimulation for $40 \mathrm{~min}$, and cell lysates were subjected to Western blot analysis for $\mid \kappa B \alpha$. Numbers represent relative densitometric levels. One experiment out of three is shown.

signaling, is an essential transcription factor for cytokine/chemokine gene expression, we assessed the effect of DHA on NF $\kappa \mathrm{B}$ activation. Our results indicate a reduction of approximately $50 \%$ in the amounts of nuclear p65 in DC treated with DHA and LPS, and the reduction in p65 nuclear translocation correlates with DHA-mediated $\mathrm{I} \kappa \mathrm{B}$ stabilization.

Chronic activation of immune cells, including DC, plays an essential role in inflammatory/autoimmune diseases. In contrast to extensive knowledge regarding the activation of the immune system, less is known about endogenous and exogenous factors which contribute to immune deactivation or return to homeostatic levels. Recently, the n-3 unsaturated fatty acids emerged as significant agents in resolving inflammation. Understanding their actions on various immune cells will contribute to a large degree to the future development of $n-3$ fatty acids and/or their derivatives as potent anti-
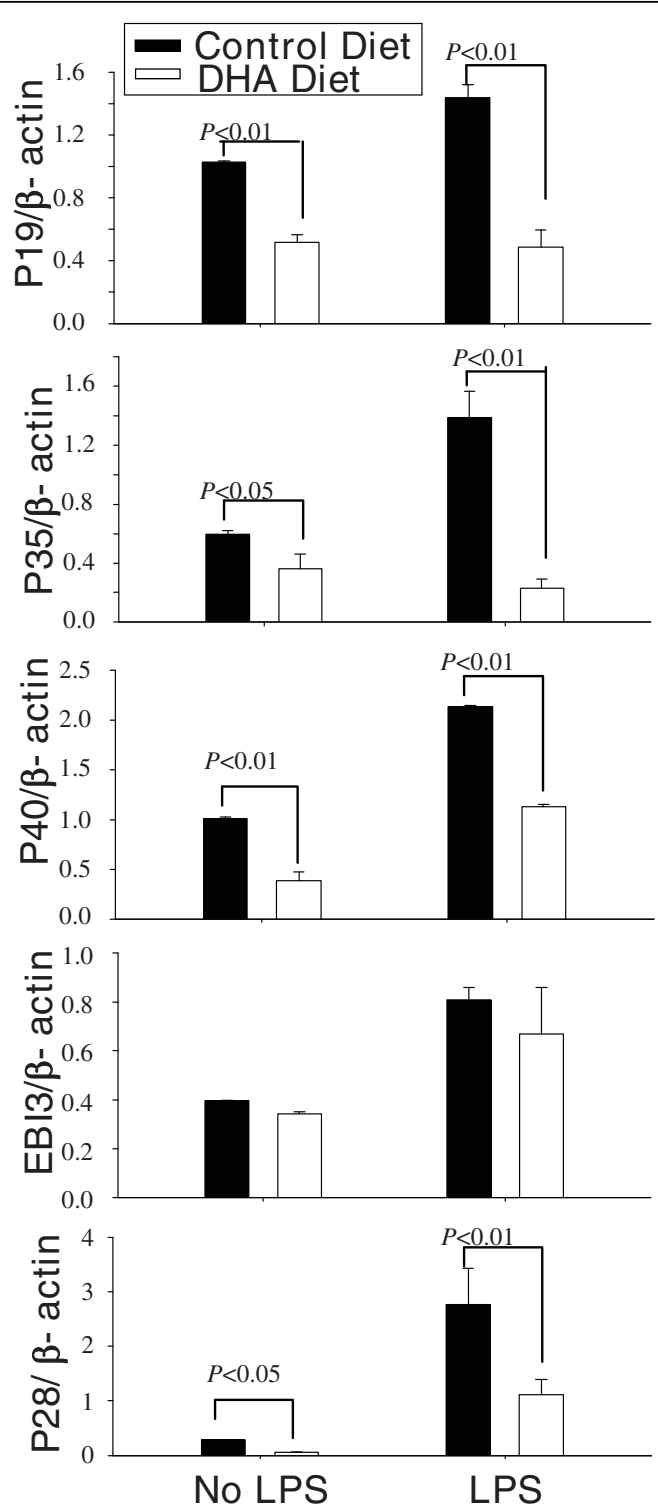

Figure 7 DHA prevents in vivo expression of IL-12 family cytokines. C57BL/6 mice were maintained for 5 wks on regular or DHA-enriched diet. Mice were injected i.p. with LPS (50 $\mu \mathrm{g}$ per mouse) and $12 \mathrm{~h}$ later spleen CD11 c+ DC were purified. Expression of p40, p35, p19, p28 and EBI3 was determined by real time RT-PCR.

inflammatory therapeutic agents in the prevention and treatment of autoimmune/inflammatory conditions.

\section{Conclusions}

In this study, exposure of bone marrow-derived DC to DHA resulted in the maintenance of an immature phenotype and drastic reduction in proinflammatory cytokine release, particularly of the IL-12 cytokine family. The effect of DHA on IL-12 expression was mediated through activation of PPAR $\gamma$ and inhibition of NF $\kappa \mathrm{B}$. Inhibition of IL-12 and IL-23 expression was also 
evident in splenic DC from mice fed a DHA-enriched diet, suggesting that dietary DHA acts as an anti-inflammatory agent in vivo.

\author{
Abbreviations \\ AA: arachidonic acid; COX: cycloxygenase; CpG: cytosine linked to a guanine \\ by a phosphate bond; DC: dendritic cells; DHA: docosahexaeoic acid; EBI3: \\ Epstein-Barr virus induced gene 3; EPA: eicosapentaenoic acid; LOX \\ lipoxygenase; PGN: proteoglycan; Polyl:C: Polyinosinic-Polycytidylic acid; \\ PPARY: peroxisome proliferator activated receptor gamma; PPRE: peroxisome \\ proliferator responsive element; PUFA: polyunsaturated fatty acids; Rosi: \\ Rosiglitazone; SUMO: small ubiquitin-like modifier; TMB: \\ tetramethylbenzidine.
}

\section{Acknowledgements}

This study was supported by the following grants: NIH/NIAID 2RO1Al052306 and Pennsylvania CURE Tobacco Settlement Formula (DG).

\section{Author details}

'Department of Physiology, Temple University School of Medicine, 3500 North Broad Street, Philadelphia, Pennsylvania 19140, USA. ${ }^{2}$ Department of Microbiology and Immunology, Temple University School of Medicine, 3500 North Broad Street, Philadelphia, Pennsylvania 19140, USA. ${ }^{3}$ Department of Biological Sciences, Kean University, 1000 Morris Avenue, Union, New Jersey 07083, USA.

\section{Authors' contributions}

WK, JHY and DG had substantial contributions to conception, design, interpretation of data and writing of the manuscript. WK, JHY, SA, MGT, EV carried out various experimental procedures. All authors read and approved the final manuscript.

\section{Competing interests}

The authors declare that they have no competing interests.

Received: 16 December 2009

Accepted: 1 February 2010 Published: 1 February 2010

\section{References}

1. Calder PC: The relationship between the fatty acid composition of immune cells and their function. Prostaglandins Leukot Essent Fatty Acids 2008, 79(3-5):101-108,

2. Chapkin RS, Kim W, Lupton JR, McMurray DN: Dietary docosahexaenoic and eicosapentaenoic acid: emerging mediators of inflammation Prostaglandins Leukot Essent Fatty Acids 2009, 81(2-3):187-191.

3. Das UN: Essential fatty acids: biochemistry, physiology and pathology. Biotechnol J 2006, 1(4):420-439.

4. Orr SK, Bazinet RP: The emerging role of docosahexaenoic acid in neuroinflammation. Curr Opin Investig Drugs 2008, 9(7):735-743.

5. Serhan CN: Resolution phase of inflammation: novel endogenous antiinflammatory and proresolving lipid mediators and pathways. Annu Rev Immunol 2007, 25:101-137.

6. Serhan CN, Chiang N, Van Dyke TE: Resolving inflammation: dual antiinflammatory and pro-resolution lipid mediators. Nat Rev Immunol 2008, 8(5):349-361.

7. Serhan CN, Yacoubian S, Yang R: Anti-inflammatory and proresolving lipid mediators. Annu Rev Pathol 2008, 3:279-312.

8. Stulnig TM: Immunomodulation by polyunsaturated fatty acids: mechanisms and effects. Int Arch Allergy Immunol 2003, 132(4):310-321.

9. Ariel $\mathrm{A}$, Serhan $\mathrm{CN}$ : Resolvins and protectins in the termination program of acute inflammation. Trends Immunol 2007, 28(4):176-183.

10. Kasuga K, Yang R, Porter TF, Agrawal N, Petasis NA, Irimia D, Toner M, Serhan CN: Rapid appearance of resolvin precursors in inflammatory exudates: novel mechanisms in resolution. J Immunol 2008, 181(12):8677-8687.

11. Serhan CN: Systems approach with inflammatory exudates uncovers novel anti-inflammatory and pro-resolving mediators. Prostaglandins Leukot Essent Fatty Acids 2008, 79(3-5):157-163.
12. Serhan CN: Controlling the resolution of acute inflammation: a new genus of dual anti-inflammatory and proresolving mediators. $J$ Periodontol 2008, 79(8 Suppl):1520-1526.

13. Wang H, Hao Q, Li QR, Yan XW, Ye S, Li YS, Li N, Li JS: Omega-3 polyunsaturated fatty acids affect lipopolysaccharide-induced maturation of dendritic cells through mitogen-activated protein kinases p38. Nutrition 2007, 23(6):474-482

14. Zapata-Gonzalez F, Rueda F, Petriz J, Domingo P, Villarroya F, Diaz-Delfin J, de Madariaga MA, Domingo JC: Human dendritic cell activities are modulated by the omega-3 fatty acid, docosahexaenoic acid, mainly through PPAR(gamma):RXR heterodimers: comparison with other polyunsaturated fatty acids. J Leukoc Biol 2008, 84(4):1172-1182.

15. Zeyda M, Saemann MD, Stuhlmeier KM, Mascher DG, Nowotny PN, Zlabinger GJ, Waldhausl W, Stulnig TM: Polyunsaturated fatty acids block dendritic cell activation and function independently of NF-kappaB activation. J Biol Chem 2005, 280(14):14293-14301.

16. Steinbrink K, Mahnke K, Grabbe S, Enk AH, Jonuleit H: Myeloid dendritic cell: From sentinel of immunity to key player of peripheral tolerance?. Hum Immunol 2009, 70(5):289-293.

17. Yamazaki S, Steinman RM: Dendritic cells as controllers of antigen-specific Foxp3+ regulatory T cells. J Dermatol Sci 2009, 54(2):69-75.

18. Camuesco D, Galvez J, Nieto A, Comalada M, Rodriguez-Cabezas ME, Concha A, Xaus J, Zarzuelo A: Dietary olive oil supplemented with fish oil, rich in EPA and DHA (n-3) polyunsaturated fatty acids, attenuates colonic inflammation in rats with DSS-induced colitis. J Nutr 2005, 135(4):687-694.

19. Leeb BF, Sautner J, Andel I, Rintelen B: Intravenous application of omega3 fatty acids in patients with active rheumatoid arthritis. The ORA-1 trial. An open pilot study. Lipids 2006, 41(1):29-34.

20. Marcheselli VL, Hong S, Lukiw WJ, Tian XH, Gronert K, Musto A, Hardy M, Gimenez JM, Chiang N, Serhan CN, et al: Novel docosanoids inhibit brain ischemia-reperfusion-mediated leukocyte infiltration and proinflammatory gene expression. J Biol Chem 2003, 278(44):43807-43817.

21. Marchioli R, Barzi F, Bomba E, Chieffo C, Di Gregorio D, Di Mascio R, Franzosi MG, Geraci E, Levantesi G, Maggioni AP, et al: Early protection against sudden death by $\mathrm{n}-3$ polyunsaturated fatty acids after myocardial infarction: time-course analysis of the results of the Gruppo Italiano per lo Studio della Sopravvivenza nell'Infarto Miocardico (GISSI)Prevenzione. Circulation 2002, 105(16):1897-1903.

22. Pluess TT, Hayoz D, Berger MM, Tappy L, Revelly JP, Michaeli B, Carpentier YA, Chiolero RL: Intravenous fish oil blunts the physiological response to endotoxin in healthy subjects. Intensive Care Med 2007, 33(5):789-797.

23. Tsou SS, Chiu WC, Yeh CL, Hou YC, Yeh SL: Effects of omega-3 fatty acids on inflammatory mediators and splenocyte cytokine mRNA expressions in rats with polymicrobial sepsis. Nutrition 2008, 24(5):484-491.

24. Welty FK, Lee KS, Lew NS, Zhou JR: Effect of soy nuts on blood pressure and lipid levels in hypertensive, prehypertensive, and normotensive postmenopausal women. Arch Intern Med 2007, 167(10):1060-1067.

25. Hudert CA, Weylandt KH, Lu Y, Wang J, Hong S, Dignass A, Serhan CN, Kang JX: Transgenic mice rich in endogenous omega-3 fatty acids are protected from colitis. Proc Natl Acad Sci USA 2006, 103(30):11276-11281.

26. Arrington JL, Chapkin RS, Switzer KC, Morris JS, McMurray DN: Dietary n-3 polyunsaturated fatty acids modulate purified murine T-cell subset activation. Clin Exp Immunol 2001, 125(3):499-507.

27. Weatherill AR, Lee JY, Zhao L, Lemay DG, Youn HS, Hwang DH: Saturated and polyunsaturated fatty acids reciprocally modulate dendritic cell functions mediated through TLR4. J Immunol 2005, 174(9):5390-5397.

28. Loscher CE, Draper E, Leavy O, Kelleher D, Mills KH, Roche HM: Conjugated linoleic acid suppresses NF-kappa B activation and IL-12 production in dendritic cells through ERK-mediated IL-10 induction. J Immunol 2005, 175(8):4990-4998.

29. Awasthi A, Riol-Blanco L, Jager A, Korn T, Pot C, Galileos G, Bettelli E, Kuchroo VK, Oukka M: Cutting edge: IL-23 receptor gfp reporter mice reveal distinct populations of IL-17-producing cells. J Immunol 2009, 182(10):5904-5908

30. Cornelissen F, van Hamburg JP, Lubberts E: The IL-12/LL-23 axis and its role in Th17 cell development, pathology and plasticity in arthritis. Curr Opin Investig Drugs 2009, 10(5):452-462. 
31. Sheibanie AF, Khayrullina T, Safadi FF, Ganea D: Prostaglandin E2 exacerbates collagen-induced arthritis in mice through the inflammatory interleukin-23/interleukin-17 axis. Arthritis Rheum 2007, 56(8):2608-2619.

32. Sheibanie AF, Yen $J H$, Khayrullina T, Emig F, Zhang M, Tuma R, Ganea D: The proinflammatory effect of prostaglandin E2 in experimental inflammatory bowel disease is mediated through the IL-23->IL-17 axis. $J$ Immunol 2007, 178(12):8138-8147.

33. Straus DS, Glass CK: Anti-inflammatory actions of PPAR ligands: new insights on cellular and molecular mechanisms. Trends Immunol 2007, 28(12):551-558.

34. Szanto A, Nagy L: The many faces of PPARgamma: anti-inflammatory by any means?. Immunobiology 2008, 213(9-10):789-803.

35. Varga T, Nagy L: Nuclear receptors, transcription factors linking lipid metabolism and immunity: the case of peroxisome proliferator-activated receptor gamma. Eur J Clin Invest 2008, 38(10):695-707.

36. de Urquiza AM, Liu S, Sjoberg M, Zetterstrom RH, Griffiths W, Sjovall J, Perlmann T: Docosahexaenoic acid, a ligand for the retinoid $\mathrm{X}$ receptor in mouse brain. Science 2000, 290(5499):2140-2144.

37. Lengqvist J, Mata De Urquiza A, Bergman AC, Willson TM, Sjovall J, Perlmann T, Griffiths WJ: Polyunsaturated fatty acids including docosahexaenoic and arachidonic acid bind to the retinoid $\mathrm{X}$ receptor alpha ligand-binding domain. Mol Cell Proteomics 2004, 3(7):692-703.

doi:10.1186/1476-511X-9-12

Cite this article as: Kong et al:: Docosahexaenoic acid prevents dendritic cell maturation and in vitro and in vivo expression of the IL-12 cytokine family. Lipids in Health and Disease 2010 9:12.

\section{Submit your next manuscript to BioMed Central and take full advantage of:}

- Convenient online submission

- Thorough peer review

- No space constraints or color figure charges

- Immediate publication on acceptance

- Inclusion in PubMed, CAS, Scopus and Google Scholar

- Research which is freely available for redistribution

Submit your manuscript at www.biomedcentral.com/submit 